\title{
Establishment and cryopreservation of liver, heart and muscle cell lines derived from the Chinese alligator (Alligator sinensis)
}

\author{
ZENG ChangJun $^{1}$, YE Qing ${ }^{2} \&$ FANG ShengGuo ${ }^{2 *}$ \\ ${ }^{1}$ College of Animal Science and Technology, Sichuan Agricultural University, Ya'an 625014, China; \\ ${ }^{2}$ The Key Laboratory of Conservation Biology for Endangered Wildlife of the Ministry of Education, State Conservation Center for Gene \\ Resources of Endangered Wildlife, College of Life Sciences, Zhejiang University, Hangzhou 310058, China
}

Received March 2, 2011; accepted May 20, 2011

\begin{abstract}
The Chinese alligator, Alligator sinensis, is a critically endangered species. A conservation project of gene resources for an endangered species first involves the preservation of organs, tissues, gametes, genomic DNA libraries and cell lines. The present study is the first to establish and cryopreserve cell lines of liver, heart and muscle tissues from the Chinese alligator. The study revealed that there was a large discrepancy in cell migration time in primary cultures among liver (11-12 d), heart (13-14 d) and muscle (17-18 d) tissue pieces. The differences in time in primary cell culture suggested that it was relatively easy to build visceral-derived cell lines for reptiles. Biological analysis showed that the population doubling time for thawed cells was approximately $36 \mathrm{~h}$. Karyotyping revealed that the frequency of Chinese alligator cells showing chromosome number as $2 n=32$ was 88.6\%-93.4\%. Chinese alligator cell lines established here provide a vital resource for research and are likely to be useful for protection of this rare and critically endangered species. Furthermore, the establishment of these methods may supply technical and theoretical support for preserving genetic resources at the cellular level for other reptile species.
\end{abstract}

Chinese alligator, conservation, tissue culture, cell line

Citation: Zeng C J, Ye Q, Fang S G. Establishment and cryopreservation of liver, heart and muscle cell lines derived from the Chinese alligator (Alligator sinensis). Chinese Sci Bull, 2011, 56: 2576-2579, doi: 10.1007/s11434-011-4622-9

The Chinese alligator, Alligator sinensis, is one of the most critically endangered species among the 23 species of crocodilians found in the world [1]. Due to loss of natural wetlands and habitat destruction, populations of the Chinese alligator continue to decline and their range is shrinking significantly [2]. Chinese alligator populations are now only restricted to the southern part of Anhui Province and the adjacent sections of Jiangsu and Zhejiang provinces $[3,4]$. Furthermore, the total population of wild Chinese alligators is probably $<130$ and is declining at annual rate of 4\%-6\% [2].

To protect this rare and endangered species, the Chinese government listed the Chinese alligator as a class I endangered species in 1972 [5]. Since 1979, Chinese alligator management focused on captive breeding, and the National Chinese Alligator Reserves were established in the Anhui

*Corresponding author (email: sgfanglab@zju.edu.cn; sgfang@mail.hz.zj.cn) and Zhejiang provinces [5]. Based on the status of the wild Chinese alligator populations, the captive populations have become a source of individuals for reintroduction. The reintroduction project of the Chinese alligator would be carried out to release captive-bred animals to suitable wild habitats, hoping to restore the wild populations of the Chinese alligator [6].

As an important part of the Chinese alligator conservation project, preservation of organs, tissues, sperm, oocytes, embryos and genomic DNA libraries are all practical options. Furthermore, modern cytogenetic methods and induced pluripotent stem cell techniques have made somatic cells an attractive resource for conserving rare and endangered species genetic materials. Until now, there have been no reports of a Chinese alligator cell line. In the present study, we established three cell lines from liver, heart and muscle tissues of the Chinese alligator and stored these at 
$-196^{\circ} \mathrm{C}$, which will provide a vital resource for the protection of this rare and critically endangered species.

\section{Materials and methods}

\subsection{Sample collection}

All tissue samples were derived from one Chinese alligator that died from attacking other Chinese alligators. This Chinese alligator specimen was transferred to the laboratory within $1 \mathrm{~h}$ of death where the muscle, liver and heart tissue samples were collected into sterilized separate tubes. The tissues were washed 3-5 times with sterilized D-Hank's medium supplemented with antibiotics (penicillin, 200 $\mathrm{IU} / \mathrm{mL}$; streptomycin, $250 \mathrm{IU} / \mathrm{mL}$ ).

\subsection{Cell cultures}

For cell culture, the modified procedure of Valleley et al. [7] was employed. Briefly, the collected samples were washed three times with DMEM medium (Hyclone, USA) plus $20 \%$ fetal bovine serum (FBS; Hyclone) and antibiotics (penicillin, $200 \mathrm{IU} / \mathrm{mL}$; streptomycin, $250 \mathrm{IU} / \mathrm{mL}$ ). All washed samples were minced into approximately $1 \mathrm{~mm}^{3}$ small pieces and transferred into flasks. All flasks were incubated at $33^{\circ} \mathrm{C}$ incubators with $5 \% \mathrm{CO}_{2}, 100 \%$ humidity. After $3-4$ $\mathrm{h}$, the samples were immersed into a solution containing 4 $\mathrm{mL}$ DMEM containing 20\% FBS, penicillin (200 IU/mL) and streptomycin $(250 \mathrm{IU} / \mathrm{mL})$. Primary cell culture and subculturing were performed according to a modified protocol of Guan et al. [8].

\subsection{Cryopreservation and recovery}

Cells in the logarithmic growth phase (80\%-90\% confluence) were harvested by rinsing the cell sheet three times in D-Hank's medium and $2 \mathrm{~mL}$ of $0.25 \%$ trypsin solution was then added. Flasks were examined under the microscope (Nikon TS100) with $37^{\circ} \mathrm{C}$ heat controller for 20-30 s. Subsequently, the flasks were shaken gently to detach cells and medium was added to terminate trypsinization. Cell suspensions were centrifuged at $200 \times g$ for $10 \mathrm{~min}$ and the supernatant removed. The harvested cells were resuspended in freezing medium containing 70\% DMEM, 10\% dimethyl sulfoxide (DMSO) (Sigma, USA) and $20 \%$ fetal bovine serum, and reached a final concentration of $1 \times 10^{7}-2 \times 10^{7}$ viable cells $/ \mathrm{mL}$. The resuspended cells were counted using a hemocytometer and dispensed into $0.25 \mathrm{~mL}$ sterile straws labeled with animal name, gender and date. The sealed straws were kept on ice for 20-30 min to allow equilibration of the DMSO, and then refrigerated at $-80^{\circ} \mathrm{C}$ overnight followed by transferring to liquid nitrogen.

To recover and reseed cells, frozen straws were taken from the liquid nitrogen and quickly thawed in $40^{\circ} \mathrm{C}$ water bath. The thawed cells were transferred to $15 \mathrm{~mL}$ tubes and centrifuged at $200 \times g$ for $5 \mathrm{~min}$. The pellet was resuspended gently in medium and cultured at $33^{\circ} \mathrm{C}$ with $5 \% \mathrm{CO}_{2}$.

\subsection{Growth curve}

The cell growth curve was employed according to protocols and procedures of Gu et al. [9] and Kong et al. [10]. Twentyfour-well plates were seeded with cells at a concentration of $3 \times 10^{4}-4 \times 10^{4}$ cells $/ \mathrm{mL}$. Data on cell growth and density were monitored and recorded each day until the plateau phase was reached. A cell growth curve was then plotted and the population doubling time was calculated from this curve.

\subsection{Chromosome analysis}

Cells were harvested at $80 \%-90 \%$ confluence. The Gbanding and karyotyping of the Chinese alligator were performed according to the protocols of Valleley et al. [7] and Lui et al. [11]. G-banding and karyotyping were analyzed and photographed using a cytogenetic workstation (Nikon 90i). For every generation, we calculated the number of chromosomes based on a minimum of 100 metaphase cells.

\section{Results and discussion}

\subsection{Cell culture and cryopreservation}

Fibroblast-like or epithelial-like cells could be seen migrating from the tissue pieces of liver, heart and muscle after explanting of 11-12, 13-14 and 17-18 d, respectively (Figure 1). The time differences observed in cell migration time of cultures indicated that it was relatively easy to build visceral-derived cell lines for reptiles. Furthermore, the muscle pieces took $18 \mathrm{~d}$ to achieve migration of primary cells, suggesting that a longer period of time is necessary for the culture of muscle tissue.

When the duration of culture was increased, cells continued to proliferate and thus subculturing was required when they reached $90 \%$ confluence. After subculturing, fibroblasts grew rapidly, gradually outgrowing and excluding other cells, such as epithelial cells [12]. After passaging, cell population growth accelerated and cells covered the entire culture surface within 6-7 d. Generally, at early growth stages of primary culture and passages, epithelial and fibroblast cells were present in the flask. According to the time difference of cell attachment and different tolerance to trypsin, purified fibroblasts could be obtained after 2-3 passages [13].

We determined that the average cell viability before and after thawing was $96.5 \%$ and $85.6 \%$, respectively. This indicated that culture conditions were appropriate and the cells had high survival rates after one freeze-thaw cycle. Thus, it seems possible to conserve the genome of the 


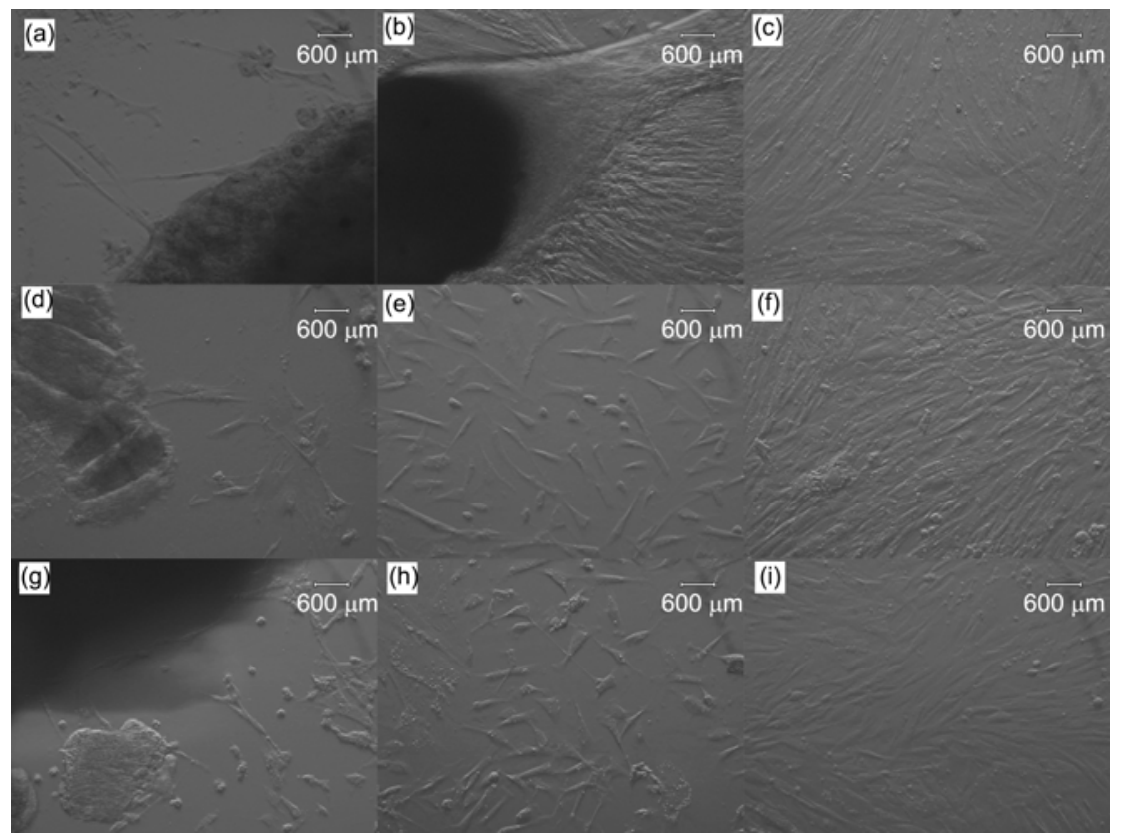

Figure 1 Morphology of liver, heart and muscle cell lines of the Chinese alligator. Fibroblast- or epithelial-like cells migrating from the tissue pieces of liver ((a), $12 \mathrm{~d})$, heart ((d),14 d) and muscle ((g), $18 \mathrm{~d})$; cells distributed over the culture surface for liver (b), heart (e) and muscle (h) tissues; cells before cryopreservation and passage (liver (c); heart (f); muscle (i)). Cells were subcultured until they reached $90 \%$ confluence.

Chinese alligator by long-term cryopreservation of cell lines in liquid nitrogen.

\subsection{Cell growth}

Crocodilians are ancient vertebrate species thought to have existed largely unchanged for 200-250 million years [7]. This particular species utilizes temperature-dependent sex determination, with $100 \%$ female hatchlings produced at an egg incubation temperature of $30^{\circ} \mathrm{C}$ and $100 \%$ male hatchlings at $33^{\circ} \mathrm{C}$ [14]. The karyotypes of a large numberof alligator embryos incubated at both $30^{\circ} \mathrm{C}$ (female producing) and $33^{\circ} \mathrm{C}$ (male producing) have been examined, and no consistent differences have been found [7]. It was reported that Valleley et al. [7] minced the American alligator (Alligator mississippiensis) embryonic tail tips and incubated these cultures at $31^{\circ} \mathrm{C}$. Cells were harvested between passages 3-8 for karyotyping. For heart tissue, the optimal temperature for the American alligator in terms of tolerance and general behavior is $32-35^{\circ} \mathrm{C}$, with a critical maximum of $38^{\circ} \mathrm{C}$ [15]. In the present study, cultured cells derived from liver, heart and muscle tissue of the Chinese alligator at $33^{\circ} \mathrm{C}$, where we could obtain primary and subcultured cells at appropriate growth speed, suggesting that this temperature was suitable for the culture of Chinese alligator fibroblast cells. In our laboratory, we have tried to culture these tissues and fibroblast cells at $37^{\circ} \mathrm{C}$ and found that the growth rate is faster than that at $33^{\circ} \mathrm{C}$. However, this temperature is unsuitable since the fibroblast-like and epithelial-like cells have apoptotic-like changes (unpublished data).

The Chinese alligator cell lines grew according to a typi- cal logarithmic growth curve (Figure 2) and the population doubling time of passaged cells was approximately $36 \mathrm{~h}$. There was a lag time of approximately $36 \mathrm{~h}$ after seeding, corresponding to the adaptation and recovery of the cells from protease damage, and then the cells proliferated rapidly and entered exponential phase. As the cell density increased, proliferation was retarded by contact inhibition where at days 6-7, cells entered the plateau phase gradually and began to degenerate. In contrast to mammals and birds, the growth speed of fibroblast cells is slower than shown for the Bengal tiger [16], chicken [8], and Simmental cattle [12]. Meanwhile, compared with the growth rate of subculture cells, fibroblast-like and epithelial-like cells needed more time growing out from minced tissue pieces, especially for primary culture. We observed that the growth rate of liver cells was faster than that of heart and muscle cells. During the processing of subculturing and passaging, the growth

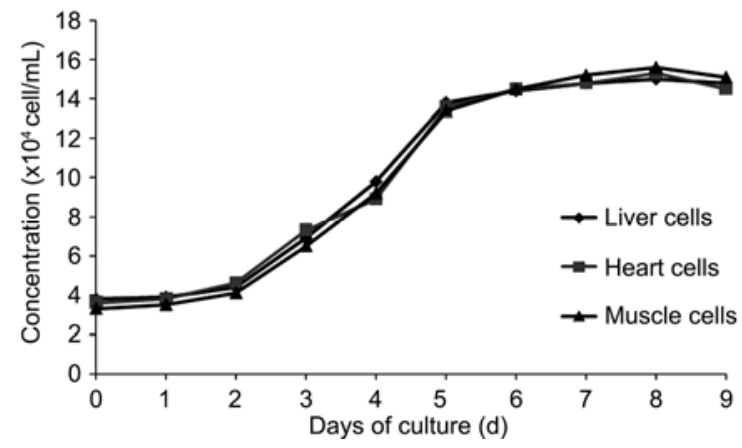

Figure 2 Growth curves of liver, heart and muscle cell lines of the Chinese alligator. 


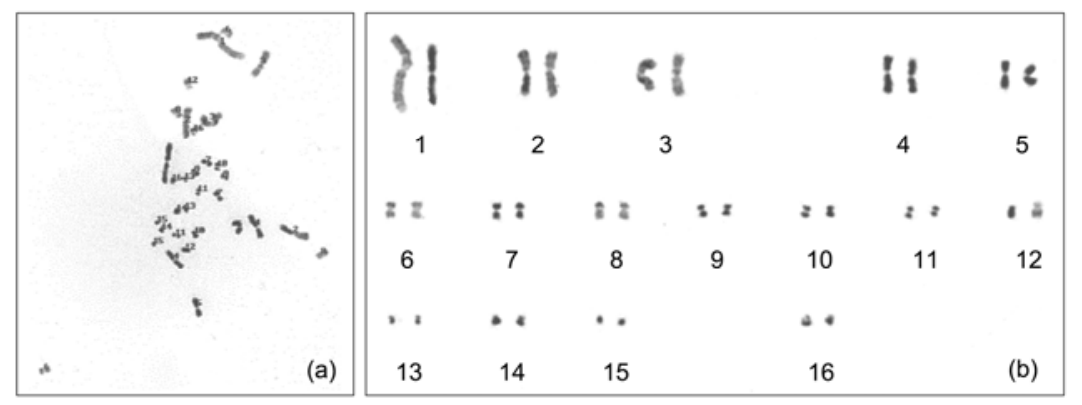

Figure 3 Metaphase chromosome (a) and karyotype (b) of the Chinese alligator.

rate of three different tissue cells showed no significant difference.

\subsection{Karyotyping}

Karyotyping of cells isolated from the Chinese alligator showed that the chromosome number was $2 n=32$, with no identifiable sex chromosomes (Figure 3). Additionally, wealso observed that the frequency of Chinese alligator cells with chromosome number $2 n=32$ was $88.6 \%-93.4 \%$. Sex chromosomes are unique in crocodilian species. G-bands in the Crocodilian have been reported as consisting of large relatively undifferentiated blocks, which may occupy whole chromosome arms [17]. Heteromorphic sex chromosomes were not identified in any of the crocodilian species $[18,19]$. The karyotypes of a large number of alligator embryos incubated at both $30^{\circ} \mathrm{C}$ (female producing) and $33^{\circ} \mathrm{C}$ (male producing) have been examined, and no consistent differences have been found, regardless of sex [7]. Comparative mapping studies showed that the X-linked gene, $Z f c$, was located on chromosome 3 of Alligator mississippiensis [7]. Thus, further chromosome mapping studies are required to determine the evolution of the $\mathrm{X}$ chromosome of crocodilian species.

In conclusion, the current study indicated that the newly established liver, heart and muscle cell lines of the Chinese alligator were stable and possessed normal biological characteristics. These characteristics suggest that the Chinese alligator cell lines would provide a useful approach for conserving this rare and endangered species in China and be an effective experimental resource for further genetics and genomics studies.

This work was supported by the National Natural Science Foundation of China (30730019) and the Fundamental Research Funds for the Central Universities of China.

1 Xu Q H, Fang S G, Wang Z W, et al. Heavy metal distribution in tissues and eggs of Chinese alligator (Alligator sinensis). Arch Environ Contam Toxicol, 2006, 50: 580-586
2 Thorbjarnarson J, Wang X M, Ming S, et al. Wild populations of the Chinese alligator approach extinction. Biol Conserv, 2002, 103: 93-102

3 Ding Y Z, Wang X M. Factors influencing the population status of wild Chinese alligators (Alligator sinensis). Biodivers Sci, 2004, 12: 324-332

4 Chen B C. The past and present situation of the Chinese alligator. As Herp Res, 1990, 3: 129-136

5 Wan Z, Gu C, Wang X, et al. Conservation, management and farming of crocodiles in China. In: Crocodiles. Proceedings of the 14th Working Meeting of the Crocodile Specialist Group. IUCN-The World Conservation Union, Gland, Switzerland and Cambridge, UK, 1998. 80-100

6 Ross J P. Crocodiles: Status Survey and Conservation Action Plan. 2nd ed. IUCN/SSC Crocodile Specialist Group, IUCN, Gland, Switzerland and Cambridge, UK, 1998

7 Valleley E M, Harrison C J, Cook Y, et al. The karyotype of Alligator mississippiensis, and chromosomal mapping of the ZFY/X homologue, Zfc. Chromosoma, 1994, 103: 502-507

8 Guan W, He X, Li L, et al. Establishment and biological characterization of fibroblast cell line from the Langshan chicken. Cell Prolif, 2010, 43: 157-163

9 Gu Y P, Li H Z, Mik J. Phenotypic characterization of telomerase-immortalized primary non-malignant and malignant tumorderived human prostate epithelial cell lines. Exp Cell Res, 2006, 312: 841-843

10 Kong D, Nishino N, Shibusawa M, et al. Establishment and characterization of human pancreatic adenocarcinoma cell line in tissue culture and the nude mouse. Tissue Cell, 2007, 39: 217-223

11 Lui J F, Valencia E F T, Boer J A. Karyotypic and analysis and chromosome biometry of cell cultures of the yellow throated alligator (caiman latirostris Daudin). Rev Brasil Genet, 1994, 17: 165-169

12 Li L F, Yue H, Ma J, et al. Establishment and characterization of a fibroblast line from Simmental cattle. Cryobiology, 2009, 59: 63-68

13 Xue Q S. The Principle and Technique of in vitro Culture. Beijing: Science Press, 2001. 432-444

14 Ferguson M W, Joanen T. Temperature of egg incubation determines sex in Alligator mississippiensis. Nature, 1982, 296: 850-853

15 Wilber C G. Effect of temperature on the heart in the alligator. Am J Physiol, 1960, 198: 861-863

16 Guan W J, Liu C Q, Li C Y, et al. Establishment and cryopreservation of a fibroblast cell line derived from Bengal tiger (Panthera tigris tigris). Cryo Letters, 2010, 31: 130-138

17 King M, Honeycutt R, Contreras N. Chromosomal repatterning in crocodiles: C, G and N-banding and the in situ hybridization of $18 \mathrm{~S}$ and 26S rRNA cistrons. Genetica, 1986, 70: 191-201

18 Cohen M M, Gans C. The chromosomes of the order Crocodilia. Cytogenetics, 1970, 9: 81-105

19 Fishman H K, Mitra J, Dowling H G. The karyotype of the Chinese alligator (Alligator sinensis). Mammal Chrom Newsl, 1968, 9: 81-82

Open Access This article is distributed under the terms of the Creative Commons Attribution License which permits any use, distribution, and reproduction in any medium, provided the original author(s) and source are credited. 